\title{
First-year Daycare and Incidence of Acute Gastroenteritis
}

\author{
Saskia Hullegie, BSc, ${ }^{a}$ Patricia Bruijning-Verhagen, MD, PhD, ${ }^{\text {a,b }}$ Cuno S.P.M. Uiterwaal, MD, PhD, ${ }^{a}$ \\ Cornelis K. van der Ent, MD, PhD, ${ }^{\mathrm{C}}$ Henriette A. Smit, PhD, ${ }^{a}$ Marieke L.A. de Hoog, PhDa
}

BACKGROUND: Daycare attendance has been associated with increased acute gastroenteritis (AGE) incidence in the first years of life. We investigated the effects of first-year daycare attendance on AGE incidence and primary care contact rate up to age 6 years.

METHODS: Children enrolled in the Wheezing Illnesses Study Leidsche Rijn cohort were managed until age 6 years. Data on primary care diagnosed AGE episodes and number of associated contacts per episode were collected from health records. Children were categorized according to first year daycare attendance and age-month at entry when applicable. Generalized estimating equations were used to assess associations between first-year daycare and AGE incidence or primary care contact rate.

RESULTS: A total of 1344 out of 2220 children (83\%) attended daycare before age 1 year. Overall, the 6-year primary care AGE incidence rate (IR) among first-year daycare attendees and nonattendees was comparable (IR: $12.2 / 100$ vs 13.3/100 child-years). Firstyear daycare attendees had a higher AGE incidence during the first year (IRR: 1.13; 95\% confidence interval: 1.06-1.21) and lower during the third to sixth year of age compared with nonattendees $(P<.001)$. The daycare-associated increase in AGE incidence was most pronounced during the first 12 months after enrollment into daycare and demonstrated clear seasonality. A similar pattern was observed for primary care contact rate per AGE episode.

concLusions: First-year daycare attendance advances the timing of AGE infections, resulting in increased AGE disease burden in the first year and relative protection thereafter. Protection against AGE infection persists at least up to age 6 years. Future studies should address whether this protective effect persists during later childhood.

\begin{abstract}
a Julius Center for Health Sciences and Primary Care, and ${ }^{c}$ Wilhelmina Children's Hospital, University Medical Center Utrecht, Utrecht, Netherlands; and ${ }^{b}$ National Institute for Public Health and the Environment (RIVM), Bilthoven, Netherlands

Ms Hullegie developed the concept of the current study as part of the Wheezing IIInesses Study Leidsche Rijn (WHISTLER) study, drafted the manuscript, and performed the statistical analyses; Dr Bruijning-Verhagen developed the concept of the current study as part of the WHISTLER study, contributed to interpreting the results, and critically revised the manuscript for important intellectual content; Dr Uiterwaal and Prof van der Ent designed and supervised the WHISTLER study and obtained funding, contributed to interpreting the results, and critically revised the manuscript for important intellectual content; Prof Smit contributed to interpreting the results and critically revised the manuscript for important intellectual content; Dr. de Hoog developed the concept of the current study as part of the WHISTLER study, contributed to interpreting the results, and critically revised the manuscript for important intellectual content; and all authors approved the version as submitted, agreed to be accountable for all aspects of the work in ensuring that questions related to the accuracy or integrity of any part of the work are appropriately investigated and resolved.
\end{abstract}

DOI: $10.1542 /$ peds.2015-3356
WHAT'S KNOWN ON THIS SUBJECT: Longitudinal studies showed that daycare attendance results in increased AGE rates at a young age, but it has also been suggested that early daycare might offer relative protection when children enter primary school.

WHAT THIS STUDY ADDS: First-year daycare attendance advances the timing of AGE infections, resulting in increased AGE disease burden in the first year and relative protection thereafter. Protection against AGE infection persists at least up to 6 years of age.

To cite: Hullegie S, Bruijning-Verhagen P, Uiterwaal CS, et al. First-year Daycare and Incidence of Acute Gastroenteritis. Pediatrics. 2016;137(5):e20153356 
Acute gastroenteritis (AGE) remains an important cause of morbidity and primary care visits in developed countries, in particular among children. In the Netherlands, the estimated incidence of AGE is 887 episodes per 1000 person-years for children 0 to 4 years old and 444 for children 5 to 10 years old. ${ }^{1}$ The incidence of AGE related primary care consultations is 45 to 92 per 1000 person-years for children 0 to 4 years old. ${ }^{2}$ In 2009 , the overall cost for gastroenteritis in the Netherlands were estimated at $€ 611$ to 695 million annually. ${ }^{3}$

Daycare centers are a suitable environment for the transmission of AGE because of close contact between children who have not yet learned adequate hygiene practices. ${ }^{4}$ Daycare attendance during preschool age is associated with an increased incidence of several infections, including AGE. ${ }^{5-10}$ Consequently, increased rates of primary care consultation, hospitalization, and medication prescription have been reported for infants attending daycare compared with those cared for at home. . $^{3,5,9,11-14}$ Although it is known that early daycare attendance is associated with an increased incidence and economic burden of AGE, it has also been suggested that early daycare may offer relative protection from AGE when children enter primary school. ${ }^{8,15,16}$ The duration and magnitude of such opposite effects of early daycare exposure, however, remain unclear, and consequently the cumulative impact of daycare attendance on AGE disease burden during childhood also remains unclear.

The aim of this cohort study was to assess the effects of first-year daycare attendance on the number and timing of primary care diagnosed AGE episodes and consultations up to the age of 6 years as a measure for AGE disease burden during childhood.

\section{METHODS}

\section{Participants}

All children in the current study were participants in the Wheezing Illnesses Study Leidsche Rijn (WHISTLER) project, a large, prospective birth cohort study on perinatal and infant risk factors for wheezing illness. Healthy newborns in Leidsche Rijn were enrolled between December 2001 and December 2012. The study design and rationale of WHISTLER are described in detail elsewhere. ${ }^{17}$ Briefly, parents of newborns were invited by telephone to participate within 2 months after birth and the newborns were managed monthly during the first year of life. Exclusion criteria at baseline were gestational age $<36$ weeks, major congenital abnormalities, and neonatal respiratory disease. The study was approved by the pediatric medical ethics committee of the University Medical Center Utrecht, and written informed consent was obtained from the parents.

\section{Data Collection}

At baseline, data were collected on prenatal risk factors and parental characteristics. Data on postnatal risk factors, such as daycare attendance and duration of breastfeeding, were collected prospectively by monthly questionnaires during the first 12 consecutive months. Follow-up of participants included extraction of 6 years of relevant medical data from the primary care electronic medical database using the International Classification system of Primary Care. ${ }^{18}$ Specifically, we extracted data on AGE related primary care consultations for all participants with a general practitioner (GP) practicing within the Leidsche Rijn research district. GP follow-up years for the participants were included until the sixth birthday of the child, and birth enrollment was defined as being registered at a GP practice before the age of 6 months. In the Dutch health care system, each individual is obligatory insured for standard medical care and listed with a GP. ${ }^{19}$ Dutch primary care, with GPs serving as gatekeepers for secondary health care, is a strong foundation of the health care system. With their position at the core of the health care system, GP databases provide a comprehensive collection of health care usage of each individual.

\section{Definition of Outcomes}

The primary outcome measure, a primary care-diagnosed episode of AGE during the first 6 years of life, was defined as International Classification system of Primary Care code D11 (diarrhea), D70 (gastrointestinal infection), or D73 (gastroenteritis presumed infection). A new episode of AGE was documented after a consultation-free interval of at least 28 days. For each AGE episode, additional data on the number of AGE-related primary care consultations was extracted. The secondary outcome measure was defined as the total number of AGErelated primary care consultations during the first 6 years of life.

\section{Definition of Exposure and Confounders}

The exposure variables of interest were daycare attendance in the first year of life and age of entry, which was defined as the age at which a child first entered daycare for at least 1 half day per week. Age of entry was categorized as: (1) no daycare in the first year of life (reference group); and start of daycare (2) before 3 months of age, (3) from 3 to 5 months of age, and (4) 6 to 12 months of age. Gender, parental educational level (as a measure for socioeconomic status [SES]), presence of older siblings (yes/no), and duration of exclusive breastfeeding were considered potential confounders. High educational level was defined as 1 or both parents having completed at least vocational or university education, and middle/low level was defined as 1 or both parents having 
completed education lower than at the vocational or university level. Duration of exclusive breastfeeding was divided into 4 categories: no breastfeeding, 1 to 3 months, 4 to 6 months, and $>6$ months.

\section{Statistical Analysis}

$\chi^{2}$ tests to provide a descriptive profile of the characteristics of the children studied according to firstyear daycare attendance. The crude AGE incidence rate per 100 childyears was calculated by dividing the total number of AGE episodes by the total child-years of follow-up. The AGE incidence rate was calculated per 1-year age categories up to 6 years of age. Primary care follow-up duration was calculated as the time from birth, or from the registration date at a primary care practice if this occurred beyond 6 months of age, until the last known date of follow-up or the sixth birthday, whichever came first. Rotavirus and norovirus, the most important pathogens causing AGE in infants, exhibit profound seasonality in the Netherlands, where rotavirus vaccination is not in use. ${ }^{20}$ We indirectly explored these pathogens' contribution to AGE by assessing seasonal patterns in incidence rates by first year daycare status and across various age groups.

Because of missing values for parent- and child-related factors, a substantial proportion of the cases could not be used in the regression analysis. To address the potential bias incurred by using complete case analysis, we imputed missing values using the multivariate imputations by chained equations procedure in SPSS (version 20.0; IBM SPSS Statistics, IBM Corporation). ${ }^{21}$ We performed separate analyses for complete cases and for imputed data. The 10 imputed data sets were analyzed and the results were combined. We averaged estimates of the variables to give a single mean estimate and adjusted SEs according to Rubin's rule. ${ }^{22}$
Generalized estimating equations (GEE) were used to assess the association between first-year daycare attendance and incidence of AGE episodes, with no daycare in the first year of life as the reference category. GEE analysis takes into account the correlation between repeated measurements for the same individual. An autoregressive correlations structure was selected to correct the correlated data. A negative binomial link function was used to correct for overdispersion of the count data. To test whether the effect of first-year daycare on AGE was age-dependent, an interaction term for daycare attendance with age was added to the GEE model. The regression coefficients reflect an incidence rate ratio (IRR).

Similar analyses were done to assess the association between first-year daycare attendance and the number of primary care consultations for AGE. The regression coefficients from this GEE model reflect an IRR. All models were adjusted for potential confounders, including gender, parental education level, presence of older siblings, and duration of exclusive breastfeeding.

All statistical analyses were performed with SPSS (version 20.0), SAS 9.2 (SAS Institute, Inc, Cary, NC) and OpenEpi (Open Source Epidemiologic Statistics for Public Health; version 3.03).

\section{RESULTS}

Of the 2464 participants recruited for the WHISTLER study, primary care follow-up data were available for 2220 children (90\%). Complete data were available for 1626 of the 2220 children (73\%) (Fig 1). Baseline characteristics of these 1626 children categorized according to daycare attendance are listed in Table 1. of the 1626 children included, 1344 $(83 \%)$ attended daycare in the first year of life for at least 1 month. The parental education level was high for $83 \%$ of the included children. On average, daycare attendees had higher-educated parents who introduced breastfeeding more often and had an older sibling less often. During the 6925 person-years of follow-up (median 4.9, maximum 6.0 years), 834 episodes of primary care-diagnosed AGE were recorded. Overall, the AGE incidence rate was highest in the first 2 years of life and declined thereafter (Table 1). Compared with children who did not attend daycare, first-year daycare attendees had a higher AGE incidence rate in the first 2 years of life, but lower incidence rates at ages 3 to 6 years. The seasonal pattern of the AGE incidence rate per 1-year age-group and by daycare status is visualized in Fig 2. A clear winter peak in the incidence rate is observed in the first year of life for first-year daycare attendees, which is compatible with rotavirus and norovirus seasonality. A similar seasonal peak is observed among children without first-year daycare during the second year of life and, to a lesser extent, for the 2- to 6-year age groups.

The following reported results pertain to the multiple imputation data set $(n=2220)$, which had comparable baseline characteristics. Results of the complete case analysis are described in Supplemental Fig 4.

\section{Impact of Daycare on Cumulative AGE Incidence}

The crude cumulative AGE incidence in the first 6 years of life is shown in Table 2. The mean 6-year incidence rate was 13.3 per 100 child-years (95\% CI: 11.9-14.8) for the no daycare group compared with 12.2 per 100 child-years (95\% CI: 11.4-13.0) for the daycare group. After adjustment for gender, parental education level, presence of older siblings, and duration of exclusive breastfeeding, no difference in cumulative 6-year AGE incidence was observed between first-year daycare 
attendees and those who did not attend daycare $(P=.19)$. Similarly, no difference in cumulative 6-year incidence was observed across strata of age at entry into daycare.

The number of primary care consultations in the first 6 years of life in the daycare group (19.3/100 child-years) was similar to that in the no daycare group (19.6/100 child-year, $P=.82$; Table 3). After adjustment for confounders, no difference in cumulative 6-year incidence of AGE-related primary care consultations was observed between first-year daycare attendees and those who did not attend daycare $(P=.82)$ Similarly, no difference in cumulative 6-year incidence was observed across strata of age at entry into daycare.

\section{Age-Dependent Effect of Daycare on AGE}

The test for interaction revealed that the associations between daycare attendance in the first year of life and incidence of AGE episodes as well as primary care consultations were age dependent $(P<.001)$. Figure $3 \mathrm{~A}$ shows the adjusted AGE IRR per 1-year age category in children with and without first-year daycare and categorized according to age of entry in daycare. We observed a significantly higher AGE incidence rate in daycare attendees during the first year of life. This increased incidence in the first year of life was observed across all 3 age-at-entry categories, with a mean IRR of 1.13 (95\% CI: 1.06-1.21). During the second year of life, the incidence rate for AGE was only significantly higher among children entering daycare after 6 months of age (IRR: 1.11; 95\% CI: 1.01-1.22). During the following years, the IRR reversed, showing overall lower AGE incidence rates in first-year daycare attendees compared with the children cared for at home. The decrease was consistent across all the age-at-entry categories, with mean IRRs varying between

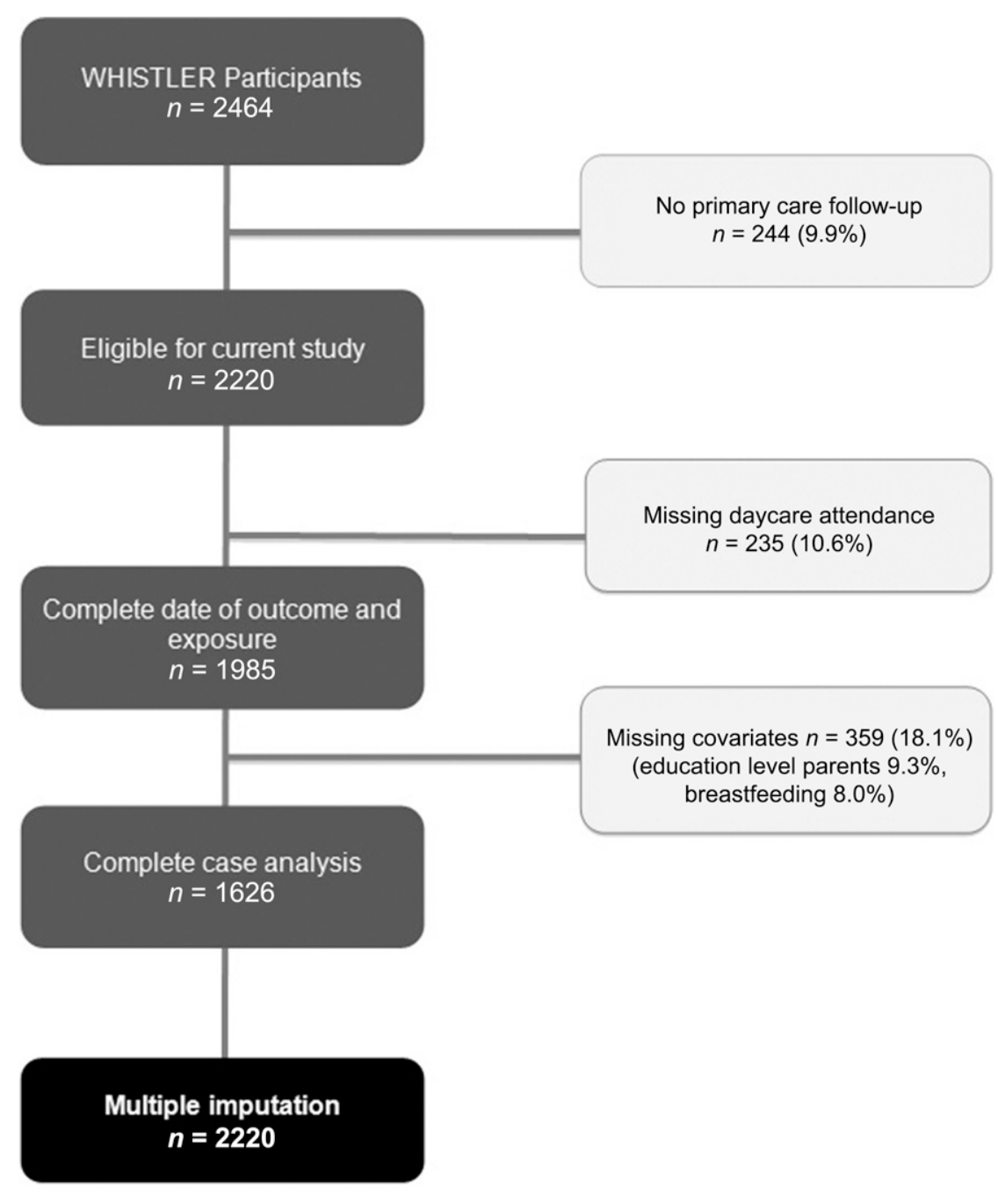

FIGURE 1

Flowchart of the study population.

0.92 and 0.95 . A similar pattern was observed for the IRR of AGE-related primary care consultations (Fig 3B). These findings are comparable with the results of the complete case analysis (Supplemental Fig 4).

\section{DISCUSSION}

This study showed higher AGE incidence rates and primary care consultations for daycare attendees during the first year of life. In the following years, the effect of early daycare on AGE rates and associated primary care consultations reversed, with persistently lower rates among daycare attendees compared with children cared for at home up to age
6 years. Similarly, the differential presence of a winter peak in AGE incidence across age groups was observed between children with and without first-year daycare attendance. Overall, the 6-year cumulative AGE incidence and AGErelated primary care consultation rates were similar for children attending and not attending daycare during the first year of life. For children starting daycare before 6 months of age, AGE incidence was increased during the first year of life only, whereas for children starting after 6 months of age, the effect persisted during the second year of life. This suggests that the impact of daycare attendance on AGE is most 
pronounced during the first year after entry into daycare.

Worldwide, the number of young children attending daycare has rapidly increased over the last few decades. ${ }^{12,23}$ In the Netherlands, $\sim 50 \%$ of the 0.7 million children aged 0 to 4 years are enrolled in daycare. ${ }^{5}$ Previous studies have demonstrated that daycare attendance is associated with a higher AGE incidence compared with children who did not attend daycare..$^{5,7,10,16}$ Our study investigated AGE incidence rates during both the period of daycare attendance and in the following years, as well as the total, cumulative AGE disease burden up to age 6 years. This detailed analysis enabled us to reveal the age-dependent effect of daycare attendance on the occurrence of AGE during childhood. Although
TABLE 1 Sociodemographic Description of the 1626 Studied Children and Their Parents

\begin{tabular}{|c|c|c|c|c|}
\hline Characteristics & $\begin{array}{l}\text { Total Population } \\
\quad(n=1626)\end{array}$ & $\begin{array}{c}\text { Daycare First } \\
\text { Year }(n=1344)\end{array}$ & $\begin{array}{l}\text { No Daycare First } \\
\text { Year }(n=282)\end{array}$ & $P$ \\
\hline \multicolumn{5}{|l|}{ Child } \\
\hline Gender (\% boy) & 49.2 & 49.4 & 48.2 & .840 \\
\hline Older siblings (\% yes) & 50.7 & 49.6 & 56.7 & .03 \\
\hline $\begin{array}{l}\text { Excl breastfeeding duration } \\
\text { (\%) }\end{array}$ & & & & $<.001$ \\
\hline No & 19.7 & 18.2 & 27.0 & \\
\hline $1-3 \mathrm{mo}$ & 48.6 & 49.9 & 42.6 & \\
\hline $4-6 \mathrm{mo}$ & 19.2 & 20.5 & 13.1 & \\
\hline$>6 \mathrm{mo}$ & 12.4 & 11.4 & 17.4 & \\
\hline Parents & & & & $<.001$ \\
\hline \multicolumn{5}{|l|}{ Educational level (\%) } \\
\hline High & 83.0 & 88.2 & 58.5 & \\
\hline Middle/low & 17.0 & 11.8 & 41.5 & \\
\hline \multicolumn{5}{|l|}{$\begin{array}{l}\text { IRR of AGE per age } \\
\text { category/100 child-years } \\
(95 \% \mathrm{Cl})\end{array}$} \\
\hline $0-1$ y & $25.5(23.1-28.2)$ & $\begin{array}{c}27.9(25.1- \\
30.9)\end{array}$ & $14.3(10.3-19.5)$ & $<.001$ \\
\hline $1-2 y$ & $14.3(12.4-16.3)$ & $\begin{array}{c}14.9(12.9- \\
17.2)\end{array}$ & $11.1(7.6-15.8)$ & .14 \\
\hline $2-3 y$ & $7.5(6.1-9.2)$ & $6.3(4.9-8.0)$ & $13.0(9.0-18.2)$ & .002 \\
\hline $3-4 y$ & $6.1(3.0-7.7)$ & $4.1(2.9-5.6)$ & $14.7(10.1-20.8)$ & $<.001$ \\
\hline $4-5$ y & $4.2(3.0-5.7)$ & $2.9(1.8-4.4)$ & $9.1(5.4-14.5)$ & .001 \\
\hline $5-6 y$ & $4.9(3.4-6.7)$ & $3.2(2.0-5.0)$ & $11.1(6.6-17.8)$ & $<.001$ \\
\hline
\end{tabular}

excl, exclusive

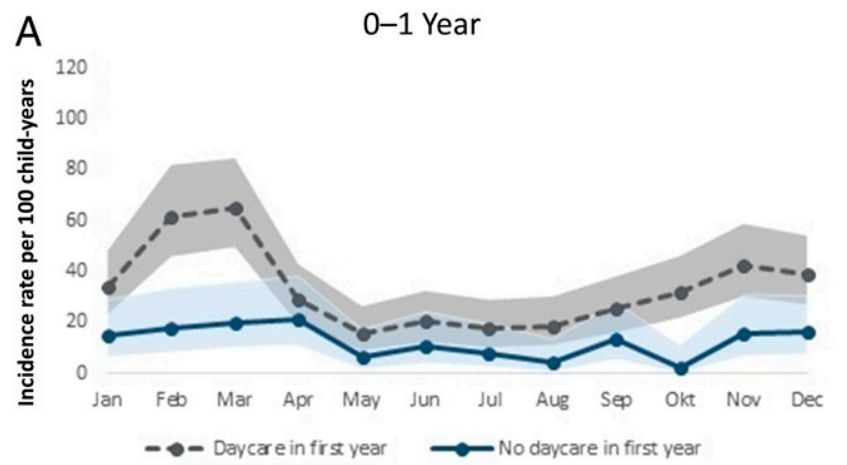

C

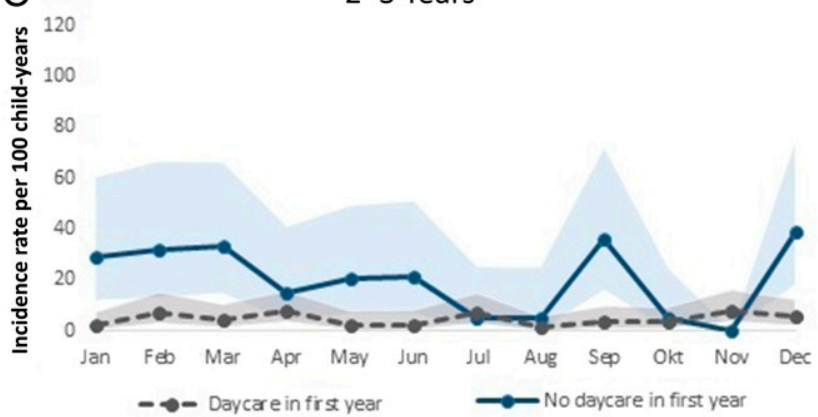

B

1-2 Years

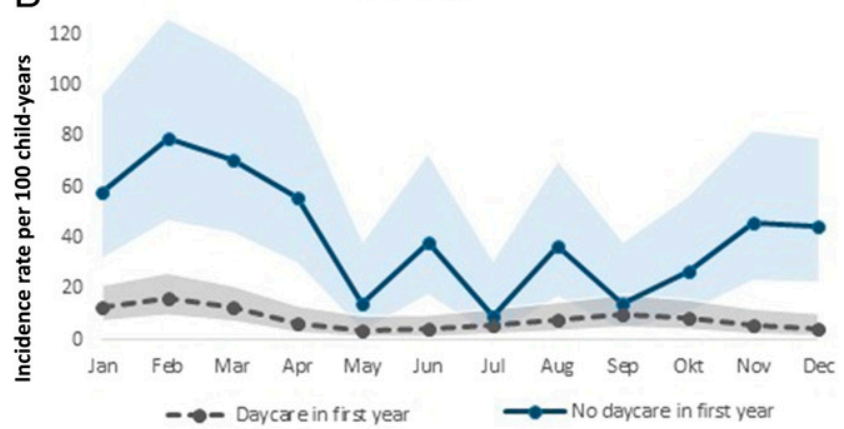

D

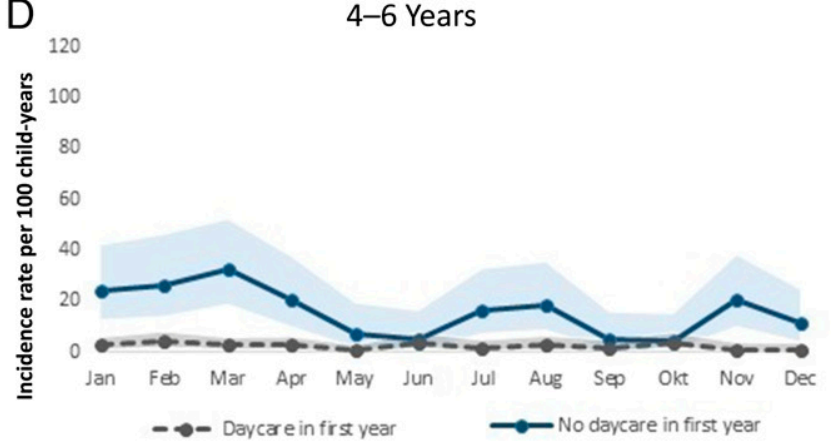

FIGURE 2

Seasonal pattern of AGE incidence in children with and without first-year daycare across various age groups. The gray and blue areas represent 95\% Cls for AGE incidence rates in children with and without first-year daycare attendance, respectively. 
daycare attendees have higher rates of AGE during the first year and part of the second year of life, the overall number of GP-attended AGE episodes and consultations up to age 6 years was not increased. Our findings are in line with results from 2 other prospective cohort studies that assessed direct and long-term effects of early daycare on AGE occurrence. Côté et al ${ }^{15}$ did not find a difference in cumulative parentreported AGE incidence in the first 8 years of life between children attending daycare before ages 2.5 years and those not attending daycare. Zutavern et $\mathrm{al}^{8}$ found an increased risk, based on parental questionnaires, of several infections, including AGE, in the first years of life for children who entered daycare before 2 years of age, and observed that this risk disappeared or even reversed from the age of 4 years on. In our study, AGE occurrence was determined based on GP records, reflecting disease episodes that were sufficiently severe to seek health care. As in the Dutch health care system, GPs act as gatekeepers for secondary care.

TABLE 2 Cumulative AGE Incidence in Children With and Without First-year Daycare Attendance up to Age 6 Years

\begin{tabular}{|c|c|c|c|c|}
\hline $\begin{array}{l}\text { Primary Care Diagnosed } \\
\text { AGE }\end{array}$ & $\begin{array}{c}\text { Number } \\
\text { of AGE } \\
\text { Episodes }\end{array}$ & Child-years & $\begin{array}{l}\text { Rate/100 Child-years } \\
\qquad(95 \% \mathrm{Cl})\end{array}$ & Adjusted $^{\mathrm{a}}$ IRR $(95 \% \mathrm{Cl})$ \\
\hline $\begin{array}{l}\text { No daycare in first year } \\
\quad(n=522)\end{array}$ & 318 & 2392.7 & $13.3(11.9-14.8)$ & 1.00 \\
\hline $\begin{array}{l}\text { Daycare in first year ( } n \\
\quad=1698 \text { ) } \\
\text { Age at entry: }\end{array}$ & 876 & 7187.4 & $12.2(11.4-13.0)$ & $0.93(0.75-1.09)$ \\
\hline 0 to 2 mo & 112 & 1091.0 & $10.3(8.5-12.3)$ & $0.97(0.72-1.32)$ \\
\hline 3 to $5 \mathrm{mo}$ & 607 & 4971.7 & $12.2(11.3-13.2)$ & $0.92(0.74-1.15)$ \\
\hline 6 to $12 \mathrm{mo}$ & 157 & 1124.7 & $14.0(11.9-16.3)$ & $1.08(0.80-1.46)$ \\
\hline
\end{tabular}

adjusted for: gender, parental education level, older siblings and duration of exclusive breastfeeding

TABLE 3 Cumulative Incidence of AGE Primary Care Consultations With and Without First-Year Daycare Attendance up to Age 6 Years

\begin{tabular}{lcccc}
\hline $\begin{array}{l}\text { Primary Care Diagnosed } \\
\text { AGE Infection }\end{array}$ & $\begin{array}{c}\text { Primary Care } \\
\text { Consultations }\end{array}$ & Child-years & $\begin{array}{c}\text { Rate/100 Child- } \\
\text { years (95\% CI) }\end{array}$ & $\begin{array}{c}\text { Adjusteda IRR (95\% CI) } \\
\text { GEE }\end{array}$ \\
\hline $\begin{array}{l}\text { No daycare in first year } \\
\quad(n=522)\end{array}$ & 468 & 2392.7 & $19.6(17.9-21.4)$ & 1.00 \\
$\begin{array}{l}\text { Daycare in first year }(n \\
\quad \text { 1698) }\end{array}$ & 1389 & 7187.4 & $19.3(18.3-20.4)$ & $0.99(0.77-1.28)$ \\
$\begin{array}{l}\text { Age at entry } \\
\text { 0-2 mo }\end{array}$ & & & & \\
3-5 mo & 177 & 1091.0 & $16.2(14.0-18.8)$ & $0.81(0.77-1.59)$ \\
6-12 mo & 972 & 4971.7 & $19.6(18.4-20.8)$ & $1.00(0.77-1.31)$ \\
\hline
\end{tabular}

${ }^{a}$ Adjusted for: gender, parental education level, older siblings, and duration of exclusive breastfeeding.

We therefore feel confident that we have captured all medically attended AGE episodes. Unfortunately, our study did not provide data about
GP referrals to secondary care, including hospitalization. Whether the proportion of AGE episodes referred to secondary care differs
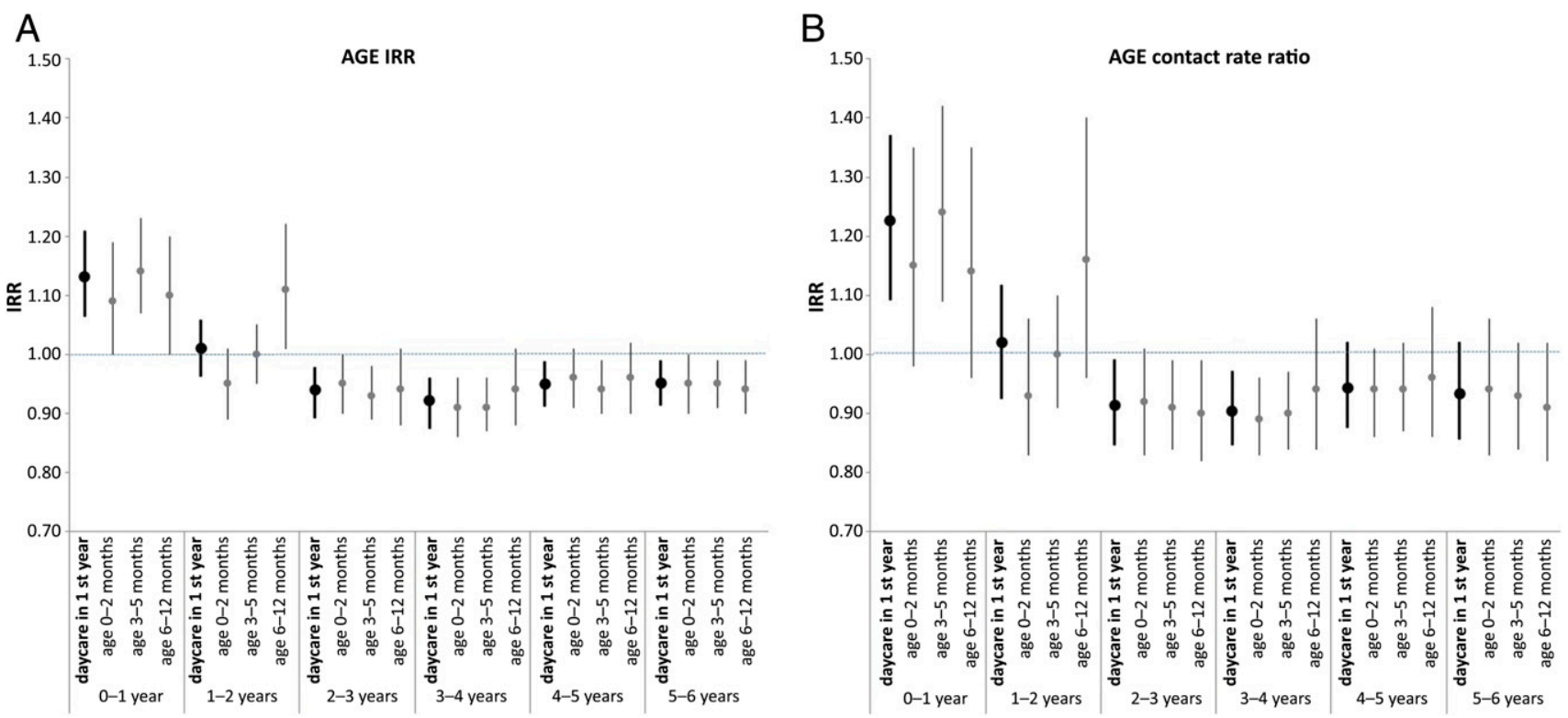

FIGURE 3

Adjusted incidence rate ratios comparing AGE incidence (A) and AGE primary care consultation rate (B) in children with and without first-year daycare, categorized according to age at entry (no daycare in the first year is the reference group). Adjusted for: gender, parental education level, siblings, and duration of exclusive breastfeeding. 
according to first-year daycare exposure status can therefore not be assessed in our study. However, in a national health care database study from Denmark, first-year daycare attendance was not associated with increased cumulative rates of AGE hospitalization up to age 5 years, although a difference in the age at the time of hospitalization was observed between the daycare and no daycare groups, similar to findings in our study. ${ }^{24}$ Together, these studies indicate that early daycare does not increase overall AGE disease severity or health care burden, but does influence timing of AGE events.

Previous studies have shown that most children suffer from AGE immediately after enrollment in daycare centers. ${ }^{7,15,16,24}$ Depending on age at entry, the increase in AGE incidence among daycare attendees was observed in our study during the first or first and second year only. The seasonal peak during winter months suggests an important contribution of rotavirus and norovirus to the increased AGE incidence for first-year daycare attendees. By contrast, children who did not attend daycare during the first year appear to encounter these seasonal infections during later years. It appears that exposure to high levels of enteropathogens in the daycare environment results in early first infection, ${ }^{25}$ which is often symptomatic, and induces subsequent immunity that is protective against symptomatic disease in later school-age years.

The major strengths of our study are its large size, the prospective study design, and the follow-up duration of 6 years. Furthermore, the study outcome, AGE, has been extracted from primary care medical records and collected independently of exposure status, which minimizes information bias. Although health care seeking behavior may differ among parents, it has been demonstrated in a recent Dutch study not to be associated with daycare attendance for children 0 to 4 years old, minimizing the potential for bias introduction in this study. ${ }^{9}$ Still, some methodological limitations should be considered. First, we only had information on daycare attendance in the first year of life. This could have affected the long-term results as it might overestimate the incidence in the no daycare group at the ages of 2 years or older. Some of the children classified as having had no daycare in the reference group might be exposed to daycare after the first year of life, likely resulting in an underestimation of the effect of daycare. Secondly, the data did not allow us to further specify daycare into type or size of the daycare facility. Previous studies demonstrated an increased risk of infections in the first year of life when attending large daycare centers compared with smaller daycare centers. ${ }^{8,26}$ Finally, in this study, the percentage of families with a high SES in the study population were overrepresented compared with the district population average and the children of these families are more likely to attend daycare. ${ }^{27}$ Indeed, the percentage of high SES families in the daycare group is higher in the study population compared with the Dutch average ( $80 \%$ versus $60 \%$, respectively). ${ }^{27}$ This may imply selection, nevertheless it is unlikely that this will resulted in bias, because families are included before the occurrence of AGE and exposure to daycare. Furthermore, we do not have evidence to suggest that the association between daycare attendance and AGE differs by SES.

\section{CONCLUSIONS}

This study showed that first-year daycare attendance advances the timing of AGE infections, resulting in increased AGE disease burden in the first year and relative protection thereafter. Protection persists at least up to age 6 years, resulting in an overall similar AGE disease burden between children attending and not attending daycare during the first year of life. Therefore, we conclude that early daycare does not increase overall acute gastroenteritis disease severity or health care burden and has a protective effect against AGE in later years. Future studies are needed to determine if this protective effect persists beyond the age of 6 years.

\section{ACKNOWLEDGMENTS}

We thank all parents and children who participated in the WHISTLER project and all co-workers who helped conduct the measurements, fieldwork, and data management.

ABBREVIATIONS
AGE: acute gastroenteritis
CI: confidence interval
GEE: generalized estimating
$\quad$ equations
GP: general practitioner
IRR: incidence rate ratio
RR: rate ratio
SES: socioeconomic status
WHISTLER: Wheezing Illnesses
$\quad$ Study Leidsche Rijn

Accepted for publication Feb 2, 2016

Address correspondence to Marieke de Hoog, Julius Center for Health Science and Primary Care, University Medical Center Utrecht, Stratenum 6.131, P0 Box 85500, 3508 GA Utrecht, Netherlands. E-mail: m.l.a.dehoog@umcutrecht.nl

PEDIATRICS (ISSN Numbers: Print, 0031-4005; Online, 1098-4275). 
FINANCIAL DISCLOSURE: Dr. Bruijning-Verhagen has received payment from GlaxoSmithKline for lectures on rotavirus epidemiology. The other authors have indicated they have no financial relationships relevant to this article to disclose.

FUNDING: The Wheezing IIInesses Study Leidsche Rijn project was supported by grants from the Netherlands Organization for Health Research and Development (ZonMw), by the University Medical Center Utrecht, and by an unrestricted research grant from GlaxoSmithKline. The funding agencies did not have any role in study design, data collection, analysis and interpretation of data, the writing of the article, or the decision to submit it for publication.

POTENTIAL CONFLICT OF INTEREST: The authors have indicated they have no potential conflicts of interest to disclose.

\section{REFERENCES}

1. de Wit MAS, Koopmans MPG, Kortbeek LM EA. Sensor, a population-based cohort study on gastroenteritidis in the Netherlands, incidence and etiology. Am J Epidemiol. 2001;154(7):666-674

2. de Wit MAS, Koopmans MPG, Kortbeek LM, et al. Gastroenteritis in sentinel general practices, the Netherlands. Emerg Infect Dis. 2001:7(1):82-91

3. Friesema IHM, Lugnér AK, van Duynhoven YT; GEops Working Group. Costs of gastroenteritis in the Netherlands, with special attention for severe cases. Eur J Clin Microbiol Infect Dis. 2012;31(8):1895-1900 10.1007/s10096-011-1518-1

4. Roberts L, Jorm L, Patel M, Smith W, Douglas RM, McGilchrist C. Effect of infection control measures on the frequency of diarrheal episodes in child care: a randomized, controlled trial. Pediatrics. 2000;105(4 pt 1):743-746

5. Enserink R, Ypma R, Donker GA, Smit $H A$, van Pelt W. Infectious disease burden related to child day care in the Netherlands. Pediatr Infect Dis J. 2013;32(8):e334-e340 10.1097/ INF.0b013e318290601e

6. Bradley RH; National Institute of Child Health and Human Development (NICHD) Early Child Care Research Network. Child care and common communicable illnesses in children aged 37 to 54 months. Arch Pediatr Adolesc Med. 2003;157(2):196-200 www.ncbi.nlm.nih.gov/pubmed/ 12580692. Accessed April 3, 2015

7. National Institute of Child Health and Human Development Early Child Care Research Network. Child care and common communicable illnesses: Results from the National Institute of Child Health and Human Development Study of Early Child Care. Arch Pediatr Adolesc Med. 2001;155(4):481-488 www.ncbi.nlm.nih.gov/pubmed/ 11296076. Accessed April 3, 2015

8. Zutavern A, Rzehak P, Brockow I, et al; LISA Study Group. Day care in relation to respiratory-tract and gastrointestinal infections in a German birth cohort study. Acta Paediatr. 2007;96(10):1494-1499 10.1111/j.1651-2227.2007.00412.x

9. Enserink R, Lugnér A, Suijkerbuijk A, Bruijning-Verhagen P, Smit HA, van Pelt W. Gastrointestinal and respiratory illness in children that do and do not attend child day care centers: a cost-of-illness study. PLoS One. 2014;9(8):e104940 10.1371/journal. pone. 0104940

10. Lu N, Samuels ME, Shi L, Baker SL, Glover SH, Sanders JM. Child day care risks of common infectious diseases revisited. Child Care Health Dev. 2004;30(4):361-368 10.1111/j.1365-2214.2004.00411.x

11. Heyworth JS, Jardine A, Glonek G, Maynard EJ. Incidence, impact on the family and cost of gastroenteritis among 4 to 6-year-old children in South Australia. J Gastroenterol Hepatol. 2006;21(8):1320-1325 10.1111/j.1440-1746.2006.04142.x

12. Silverstein M, Sales AE, Koepsell TD. Health care utilization and expenditures associated with child care attendance: a nationally representative sample. Pediatrics. 2003;111(4 pt 1). Available at: www. pediatrics.org/cgi/content/full/111/ $4 \mathrm{pt} 1 / \mathrm{e} 371$

13. Ogilvie I, Khoury H, Goetghebeur MM, El Khoury AC, Giaquinto C. Burden of community-acquired and nosocomial rotavirus gastroenteritis in the pediatric population of Western Europe: A scoping review. BMC Infect Dis. 2012;12:62 10.1186/1471-233412-62
14. Thrane N, Olesen C, Md JT, Søndergaard C, Schønheyder HC, Sørensen HT. Influence of day care attendance on the use of systemic antibiotics in 0- to 2-year-old children Pediatrics. 2001;107(5). Available at: www.pediatrics.org/cgi/content/full/ 107/5/E76

15. Côté SM, Petitclerc A, Raynault M-F, et al. Short- and long-term risk of infections as a function of group child care attendance: An 8-year populationbased study. Arch Pediatr Adolesc Med. 2010;164(12):1132-1137 10.1001/ archpediatrics.2010.216

16. Enserink R, Simonsen J, Mughini-Gras L, Ethelberg S, van Pelt W, Mølbak K. Transient and sustained effects of child-care attendance on hospital admission for gastroenteritis. Int $J$ Epidemiol. 2015;44(3):988-997

17. Katier N, Uiterwaal CSPM, de Jong BM, et al; Wheezing IIInesses Study Leidsche Rijn Study Group. The Wheezing IIInesses Study Leidsche Rijn (WHISTLER): Rationale and design. Eur J Epidemiol. 2004;19(9):895-903

18. Verbeke M, Schrans D, Deroose S, De Maeseneer J. The International Classification of Primary Care (ICPC2): An essential tool in the EPR of the GP. Stud Health Technol Inform. 2006;124:809-814

19. Schäfer W, Kroneman M, Boerma $W$, et al. The Netherlands: Health system review. Health Syst Transit. 2010;12(1):v-xxvii, 1-228

20. Bruijning-Verhagen P, Sankatsing V, Kunst A, et al. Rotavirus-related hospitalizations are responsible for high seasonal peaks in all-cause pediatric hospitalizations. Pediatr Infect Dis J. 2012;31(12):e244-e249

21. Runin, DB. Multiple imputation after 18+ years. JASA.1996:91(434):473-489 
22. Rubin DB, Schenker N. Multiple imputation in health-care databases: an overview and some applications. Stat Med. 1991;10(4):585-598

23. Rosenfeldt V, Vesikari T, Pang X-L, Zeng S-Q, Tvede M, Paerregaard A. Viral etiology and incidence of acute gastroenteritis in young children attending day-care centers. Pediatr Infect Dis J. 2005;24(11):962-965

24. Kamper-Jørgensen M, Andersen LG, Simonsen J, Sørup S. Child care is not a substantial risk factor for gastrointestinal infection hospitalization. Pediatrics. 2008 122(6). Available at: www.pediatrics. org/cgi/content/full/122/6/e1168

25. Enserink R, Scholts R, BruijningVerhagen $\mathrm{P}$, et al. High detection rates of enteropathogens in asymptomatic children attending day care. PLOS One. 2014;9(2):e89496 10.1371/journal. pone. 0089496

26. Ball TM, Holberg CJ, Aldous MB, Martinez FD, Wright AL. Influence of attendance at day care on the common cold from birth through 13 years of age. Arch Pediatr Adolesc Med. 2002;156(2):

$$
\text { 121-126 }
$$

27. van Oploo M, Engelen M. Tweemeting trendonderzoek kinderopvang eindrapport [Trend research in childcare]. Available at: https:// www.rijksoverheid.nl/documenten/ rapporten/2007/05/14/tweemetingtrendonderzoek-kinderopvang. Accessed April 4, 2015 
First-year Daycare and Incidence of Acute Gastroenteritis

Saskia Hullegie, Patricia Bruijning-Verhagen, Cuno S.P.M. Uiterwaal, Cornelis K. van der Ent, Henriette A. Smit and Marieke L.A. de Hoog Pediatrics 2016;137;; originally published online April 25, 2016; DOI: $10.1542 /$ peds. $2015-3356$

\section{Updated Information \&} Services

Supplementary Material

References

Subspecialty Collections

Permissions \& Licensing

Reprints including high resolution figures, can be found at: /content/137/5/e20153356.full.html

Supplementary material can be found at: /content/suppl/2016/04/20/peds.2015-3356.DCSupplemental. html

This article cites 26 articles, 5 of which can be accessed free at: /content/137/5/e20153356.full.html\#ref-list-1

This article, along with others on similar topics, appears in the following collection(s):

Infectious Disease

/cgi/collection/infectious_diseases_sub

Epidemiology

/cgi/collection/epidemiology_sub

Public Health

/cgi/collection/public_health_sub

Information about reproducing this article in parts (figures, tables) or in its entirety can be found online at:

/site/misc/Permissions.xhtml

Information about ordering reprints can be found online: /site/misc/reprints.xhtml

PEDIATRICS is the official journal of the American Academy of Pediatrics. A monthly publication, it has been published continuously since 1948. PEDIATRICS is owned, published, and trademarked by the American Academy of Pediatrics, 141 Northwest Point Boulevard, Elk Grove Village, Illinois, 60007. Copyright @ 2016 by the American Academy of Pediatrics. All rights reserved. Print ISSN: 0031-4005. Online ISSN: 1098-4275.

\section{American Academy of Pediatrics}




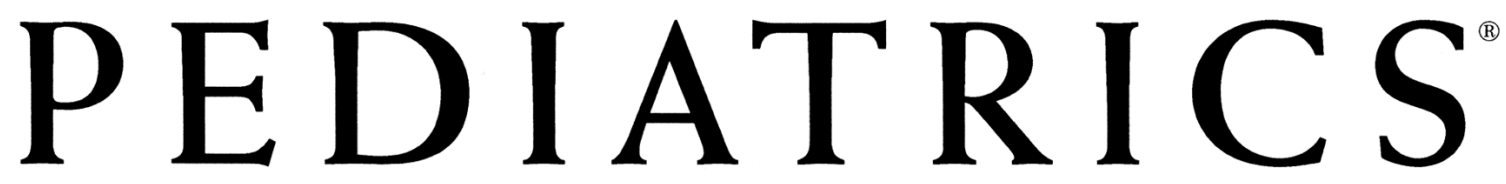

OFFICIAL JOURNAL OF THE AMERICAN ACADEMY OF PEDIATRICS

First-year Daycare and Incidence of Acute Gastroenteritis

Saskia Hullegie, Patricia Bruijning-Verhagen, Cuno S.P.M. Uiterwaal, Cornelis K. van der Ent, Henriette A. Smit and Marieke L.A. de Hoog Pediatrics 2016;137;; originally published online April 25, 2016;

DOI: $10.1542 /$ peds.2015-3356

The online version of this article, along with updated information and services, is located on the World Wide Web at: /content/137/5/e20153356.full.html

PEDIATRICS is the official journal of the American Academy of Pediatrics. A monthly publication, it has been published continuously since 1948. PEDIATRICS is owned, published, and trademarked by the American Academy of Pediatrics, 141 Northwest Point Boulevard, Elk Grove Village, Illinois, 60007. Copyright (C) 2016 by the American Academy of Pediatrics. All rights reserved. Print ISSN: 0031-4005. Online ISSN: 1098-4275.

\section{American Academy of Pediatrics}

DEDICATED TO THE HEALTH OF ALL CHILDREN ${ }^{\mathrm{m}}$ 